\title{
Anxiety and depression in parents of disabled children
}

\author{
Sălceanu Claudia \\ "Ovidius" University of Constanta, Romania \\ claudiasalceanu@yahoo.com \\ Sandu Mihaela Luminița \\ “Ovidius" University of Constanta, Romania \\ mihaelannaidin@yahoo.com
}

\begin{abstract}
Having a disabled child can add new challenges for parents and can affect, in different ways, the entire family and its way of life. Two of the most frequent consequences of having to take care of a disabled child are anxiety and depression. A sample of 30 adults (15 parents with disabled children and 15 parents with normal children) has been assessed with Beck Depression Inventory and with Cattell's Anxiety Questionnaire. The main objectives of the study aim to identify if there are significant differences between the two categories of parents regarding anxiety and depression, and if there is a significant statistical correlation between the two personality traits. The results show higher anxiety and depression levels for parents of disabled children, and a significant correlation between the two traits. The practical implications of the study are discussed in the end.
\end{abstract}

Keywords. Anxiety, depression, parents, disabled children

\section{Introduction}

Bringing up a child is hard enough for any family, but for the parent of a disabled child, worries about their future can be overwhelming, especially because these parents often lack the financial and professional support necessary. Things like the fact that they are not alone, that they deserve to be cared for, that they have to make time to enjoy their children, even though they are disabled, that they have to sometimes make hard decisions, that they need to forgive themselves, that they have to keep their sense of humor, that they have to celebrate little accomplishments, that they have to make time for their own marriage and not succumb to worries towards their disabled child, are just as many elements in which absence anxiety and depression can develop.

\section{The conceptualization of anxiety}

The term anxiety is part of common language and it refers to both common experience and pathological states (Klein, 2002). 
According to DSM-5 (2013, p.189), anxiety disorders include those disorders that share excessive fear and anxiety, as well as all the corresponding behavioral disturbances. While fear is an emotional response to an imminent threat, that is real or assumed, anxiety is the anticipation of a certain peril. Sometimes, the degree of fear or anxiety is attenuated by a pervasive behavior of avoidance. Panic attacks are a particular type of fear. They are not limited to anxiety disorders, as they can be found in other mental disorders.

Holdevici (2000) defines anxiety as an unspecified fear, with no connection to the external situations, that is not associated with the systematic avoidant behavior towards certain stimuli. Unlike anxiety, Holdevici (2002) defines fear as a negative emotional state that appears in the situation in which the individual meets an imminent threat. Fear and anxiety are dissociable at many levels: behavioral, neural and even pharmacological level (Grillon, Ameli, Woods, Merikangas \& Davis, 1991; Grillon, 2008; Davis, Walker, Miles \& Grillon, 2010; Robinson, Vytal, Cornwell \& Grillon, 2013).

The most common definition of anxiety describes it as the response to an ambiguous sense of danger (Walker \& Leach, 2014). The individual lives in a continuous tension and permanently feels threatened. Usually anxious people tend to be nervous and don't realize why they are scared. Patients with anxiety disorders suffer a great deal from the negative consequences of excessive anxiety, especially because it affects work and personal relationships, and it limits their activities and opportunities. This makes them avoid difficult situations, in order not to be embarrassed.

While moderate anxiety can act as a positive force, by raising the eficiency of undertaken actions, severe anxiety can decrease the individual's ability to perceive, reason and act adequately (Gavin, Creamer \& Crino, 2007).

Enăchescu (2007) states that anxiety can be defined in three ways:

1. A sentiment of imminent threat, with undetermined cause, that amplifies everything by raising the situation to the proportions of a real drama,

2. An attitude of expectancy toward a threat, that has the characteristics of an authentic state of alert, which invades a person's mind and is associated with the occurrence of an immediate catastrophe,

3. The certainty of the impossibility of acting and the feeling of one's own confusion.

Ionescu, Blanchet, Montreuil \& Doron (2013) state that many individuals with general anxiety disorder declare they feel anxious and nervous all their life. The average age for the development of the general anxiety disorder is 30 years old, and the debut of this disorder rarely takes place before the stage of adolescence. The symptoms of general anxiety disorder have the tendency to become chronic and to swing during the individual's lifetime.

Biological factors are of primary importance in anxiety disorders, as they can occur in the context of medical illness. Anxiety can be a symptom of certain medical conditions, like endocrine disorders which are characterized by too high or too low levels of the thyroid's hormones. Other medical conditions which can induce anxiety are lung, liver and heart diseases or any type of aches that have chaotic frequencies. Stress also plays a major role in the pathology of anxiety disorders, especially PTSD, which is considered the main etiological factor (Bystrisky, Khalsa, Cameron \& Schiffman, 2013).

\section{The conceptualization of depression}

Depression is a frequent phenomenon and with complex and varied features. Usually, depression is described in radical behavioral terms, emphasizing an physiological or emotional state (Kanter, Busch, Weeks \& Landes, 2008). Still, despite the many studies that have been conducted on depression and randomized trials that have examined the effects of 
treatments, many patients still don't know how to cope with daily problems caused by depressive disorders (Cuijpers, 2011).

Depression can be determined by different factors, like neurological, physiological or psychological. For example, neurotransmitter disorders, lack of affection during childhood, professional failure, unsatisfying marital life, the absence of social support, low self-esteem, alcoholism or other depressive disorders in the patient's family.

Gavin et al. (2011) show that depression is the lack of interest for any activities, that the individual once considered attractive and fun. Life is perceived as meaningless and monotonous, and the patient usually isolates himself completely from other people. According to Gilbert (2011), depression looks different depending on it's symptoms, degree, severity, length and frequency of episodes. Depression's debut may be associated with everyday life events.

According to DSM-5 (2013, p.156) the main characteristic of this disruptive emotional disorder is the persistent irritability, which has two main clinical manifestations:

1. Verbal or behavioral choleric outbursts, as a response to frustration,

2. A permanent angry mood.

There are many depression types (Ionescu et al., 2013; Grecu, Gaboș \& Raduly, 2007, p.30-32), which can be identified by a series of symptoms, as follows:

- Anxiety, apathy, sadness, mood swings,

- Low voice, neglected appearance,

- Attention problems, diminished productivity,

- Diminished physical strength, insomnia, anorexia,

- Concentration of attention towards own feelings and affects,

- Lack of interest towards hobbies and other enjoyable activities,

- Excessive guilt,

- Great sensitivity towards interpersonal relationships,

- Having the feeling of being rejected by others, isolation,

- Extreme negativism.

Grecu et al. (2007, p.30) highlight the frequencies of the characteristic symptoms in depressive patients, as follows:

Table 01 Frequencies of depressive symptoms

\begin{tabular}{|c|c|c|c|}
\hline Symptom & Frequency & Symptom & Frequency \\
\hline Insomnia & $100 \%$ & Psycho-motor slowness & $76 \%$ \\
\hline Depressive mood & $100 \%$ & Anorexia & $66 \%$ \\
\hline Crying & $94 \%$ & Pessimism & $64 \%$ \\
\hline Attention disorders & $91 \%$ & Memory disorders & $51 \%$ \\
\hline Ideas of disintegration & $82 \%$ & Suicide attempts & $35 \%$ \\
\hline Irritability & $76 \%$ & Hallucinations & $15 \%$ \\
\hline Lack of energy & $76 \%$ & & \\
\hline
\end{tabular}

Wolpe (1971, apud Gilbert, 2011) describes a theory of depression based on classical conditioning, stating that depression is a consequence of a conditioned anxiety. Wolpe makes a clear distinction between normal, neurotic and endogenous depression. He suggests that neurotic depression should be conceptualized and analyzed in terms of anxiously life situations that induce decreases of positive behaviors. 


\section{Depression and anxiety in families with disabled children}

When one parent suffers from an anxiety disorder, there is a high probability that his child also inherits such a disorder. For children, an untreated anxiety disorder may lead to poor performances and even depressive symptoms.

Mothers that suffer from depression may try to hide this disorder and fulfill their parental role, without giving any particular attention to their problems and without trying to heal it. Some mothers are absent from the relationship with their child, they have an erratic behavior and are not able to help their child solve his own problems. Usually, these children tend to be aggressive and furious.

Many families where a disabled child exists manage to accept their situation, at some point, and find the strength to go on. After accepting their situation, parents need to cope to a series of problems, like opinions of people around them, lack of social and psychological support, problems of integration in the society. They usually don't need mercy, but help, understanding and friendship. No matter what the impairment is, parents feel guilty for their child's suffering.

Riedesser \& Fisher (2007) define traumatic reaction as a defense complex in which the psycho-physical organism continues to either destroy or assimilate a foreign body that entered the system. A third possibility is to continue to live on with the trauma, which becomes a foreign body that is impossible to assimilate.

Individual therapy has good results when parents seek resources to reduce stress, depression and anxiety. Furthermore, it turns out that joining different therapy groups of parents that struggle with the same situation, can have positive results.

In most situations, mothers are the ones that feel responsible and blame themselves for the child's impairment. These women develop depression as they constantly feel and think they are not doing enough for their child, which is why their baby suffers.

Parents with impaired children are excluded from certain circles, and this influences the parents' emotional state. Financial problems also induce anxiety, depression and anger, since it may be the case that the child needs prolonged treatment, and even surgical interventions. The burn out syndrome is another important determinant of depression, through lack of sleep and the permanent need for attention that the child has.

\section{Research objectives}

This study aims to identify:

1. the differences between anxiety and depression in parents with impaired children by comparison with parents of normal children,

2. the correlation between anxiety and depression.

\section{Research hypotheses:}

1. It is assumed that there is a significant difference between parents of disabled children and parents of normal children regarding depression.

2. It is assumed that there is a significant difference between parents of disabled children and parents of normal children regarding anxiety.

3. It is assumed that there is a significant correlation between depression and anxiety.

\section{Research instruments:}

To conduct this research we used the Beck Depression Inventory and Cattell's Anxiety Questionnaire. Participants were trained to give the first answer that comes to mind that matches their usual behavior. To keep the data confidentiality were used only the 
questionnaire identification codes without mentioning personal data. Also, in order to ensure the ethics of the research, we obtained from all the participants their written consent.

\section{Lot of participants:}

Considering that normality and homogeneity conditions were not met, we applied the Mann-Whitney U Test for independent samples to verify the first two hypotheses and Spearman's correlation test for verifying the third hypothesis. Sampling was randomized and each individual was chosen entirely by chance (Sîntion \& Călin, 2014, p.116). The sample comprised 15 parents of disabled children, between 30 and 44 years old, 5 male and 10 female, and 15 parents of normal children, aged between 30 and 47 years old, 7 male and 8 female.

\section{Results}

1. It is assumed that there is a significant difference between parents of disabled children and parents of normal children regarding depression.

To verify this hypothesis we used the scores of Beck Depression Inventory. Since the distribution of scores was not normal, we used Mann-Whitney U Test for independent samples. The results are shown below:

Table 02 Mean Rank of scores - Depression

\begin{tabular}{|ll|r|r|r|}
\hline & Type of parents & N & Mean Rank & Sum of Ranks \\
\hline BDI & Disabled child & 15 & 19,70 & 295,50 \\
& Normal child & 15 & 11,30 & 169,50 \\
& Total & 30 & & \\
\hline
\end{tabular}

Table 03 Mann-Whitney U Test for independent samples -Depression

\begin{tabular}{|l|r|}
\hline & \multicolumn{1}{|c|}{ BDI } \\
\hline Mann-Whitney U & 49,500 \\
Wilcoxon W & 169,500 \\
Z & $-2,793$ \\
Asymp. Sig. (2-tailed) &, 005 \\
& \\
Exact Sig. [2*(1-tailed Sig.)] &, $008^{\mathrm{a}}$ \\
\hline
\end{tabular}

a. Not corrected for ties.

b. Grouping Variable: type of parents

We obtained a difference between parents with impaired children and parents with normal children, regarding depression. The threshold of significance is $.008, p<.01$, so the value of the coefficient is statistically significant. 
Studies on depression and well-being of families with impaired children show that parents feel over burden and stressed, and these conditions influence the development of depression (Kazmi, Perveen, Karamat \& Mehboob Khan, 2014; Azeem, Dogar, Shah, Cheema, Asmat, Akbar, Kousar \& Haider, 2013; Feizi, Najmi, Salesi, Chorami \& Hoveidafar, 2014). Some other studies have also revealed that parents of disabled children, in comparison with parents of normal children, experience higher levels of negative effects, less social and mental welfare, and significantly more physical problems; furthermore, parents would never totally accept their child's disability (Seltzer, Greenberg, Floyd, Pettee \& Hong, 2001).

Gilbert (2001) states that depression appears in different psychological areas like motivation, emotion, cognition and behavior. Depressed parents face a meaningless or hopeless future, they don't feel any attraction toward leisure and hobbies, and their life is invariable. Parents usually react with psychological stress, a feeling of loss and low selfesteem (https://www.childresearch.net/papers/rights/2013 01.html, accessed on 7.02.2019). The child may be seen as "disappointing" or as a "social obstacle" leading to shame and embarrassment. Parents may direct their anger toward others, their partner, the physician, or other families who do not have the same stress. Furthermore, some parents may feel guilt and may consider that the child is a punishment for a past sin. They may overprotect the child that they perceive as a symbol of their failure.

2. It is assumed that there is a significant difference between parents of disabled children and parents of normal children regarding anxiety.

To verify this hypothesis we used the scores of Beck Depression Inventory. Since the distribution of scores was not normal, we used Mann-Whitney U Test for independent samples. The results are shown below:

Table 04 Mean Rank of scores - Anxiety

\begin{tabular}{|ll|r|r|r|}
\hline & Type of parents & N & $\begin{array}{c}\text { Mean } \\
\text { Rank }\end{array}$ & $\begin{array}{c}\text { Sum of } \\
\text { Ranks }\end{array}$ \\
\hline Anxiety & Disabled children & 15 & 19,80 & 297,00 \\
& Normal children & 15 & 11,20 & 168,00 \\
& Total & 30 & & \\
\hline
\end{tabular}

Table 05 Mann-Whitney U Test for independent samples -Anxiety

\begin{tabular}{|l|r|}
\hline & \multicolumn{1}{|c|}{ Anxiety } \\
\hline Mann-Whitney U & 48,000 \\
Wilcoxon W & 168,000 \\
Z & $-2,767$ \\
Asymp. Sig. (2-tailed) &, 006 \\
& \\
Exact Sig. [2*(1-tailed Sig.)] &, $007^{\mathrm{a}}$ \\
\hline
\end{tabular}

a. Not corrected for ties.

b. Grouping Variable: type of parents 
We obtained a difference between parents with impaired children and parents with normal children, regarding depression. The threshold of significance is $.007, \mathrm{p}<.01$, so the value of the coefficient is statistically significant.

Holdevici (2002) states that parents with disabled children feel often threatened and they are usually nervous and very concerned with their child's health. Not knowing what to expect, what evolutions and manifestations of the impairment may occur, makes them uneasy, fearful or avoidant. Negative thoughts regarding their child may appear, and these ideas affect both psychological and physical health of the family.

Our results are also consistent with previous research on different population, that highlighted high anxiety levels in parents of impaired children (Al-Farsi, Al-Farsi, AlSharbati \& Al-Adawi, 2016), often caused by financial problems, which seems to be the most important anxious factor (Uskun \& Gundogar, 2010). Also, other studies show that area of residence, low socio-economic status, knowledge of the disability of one's child, low confidence, increased perceived burden of care and having no resources for psychological support are significant predictors of psychological distress and anxiety (Masulani-Mwale, Kauye, Gladstone \& Mathanga, 2018).

3. It is assumed that there is a significant correlation between depression and anxiety. We used Spearman's Rho correlation and obtained the results shown below:

Table 06 Spearman correlation between Depression and Anxiety

\begin{tabular}{|ll|r|r|}
\hline & & Depression & \multicolumn{2}{|c|}{ Anxiety } \\
\hline Depression & Spearman Correlation & 1 & .344 \\
& Sig. (2-tailed) & & .043 \\
& $\mathrm{~N}$ & 30 & 30 \\
Anxiety & Spearman Correlation & .344 & 1 \\
& Sig. (2-tailed) & .043 & \\
& $\mathrm{~N}$ & 30 & 30 \\
\hline
\end{tabular}

The threshold of significance is $.043, \mathrm{p}<.05$, so the value of the correlation coefficient is statistically significant.

The results show a highly significant positive correlation between depression and anxiety. These results are consistent with other studies that highlight the same significant correlation (Tabassum \& Mohsin, 2013; Bitsika \& Sharpley, 2004). It seems that for this correlation, the most significant predictor is the caregiver burden (Gallagher, Phillips, Oliver \& Carroll, 2008). Furthermore, this predictor has other components, as the cited study suggests, like guilt.

Other studies (Falk, 2012) show that both depression and anxiety have different predictors. While anxiety is related to maternal age, the mother's perceived ability to set behavioral limits for her child and symptom severity, depression is related to the child's aggression toward adults, the perceived lack of social support and an externalized parental locus of control.

Also, other studies indicate that parenting self-efficacy partially mediated the relationship between parenting stress and parental depression or anxiety, meaning that 
decreased parent self-efficacy correlated with increased depression or anxiety (Rezendes \& Scarpa, 2011).

\section{Conclusions}

The aims of the study were to assess the existence of significant differences between parents with disabled children and parents with normal children, regarding depression and anxiety, and to investigate the correlation between the two psychological traits.

Our results show that parents with impaired children are more anxious and more depressed. These results are important and should be addressed by counseling, in order to ensure an optimum rehabilitation of both children and parents.

It seems that caregiver burden is an important predictor for both depression and anxiety. So, it is really important to assist such parents to resolve their feelings, in order to be able to better take care of their children.

Financial problems seem to be a very important aspect that induces anxiety. This is an alarm signal for authorities, so that in the future, maybe, some policies may be adjusted so that families with disabled children receive more help and support.

Another important alarm signal is the care for both mental and physical health of parents with impaired children. Depression and anxiety are both related to several physical problems and could disturb the effectiveness of the parenting style. Moreover, parents' interpretation of their child's problem and their coping style with that problem are also effective factors of anxiety and depression.

These findings are important for how to train professionals so that they can address the needs of parents of children with disabilities, in order to improve family's wellbeing and the quality of the relationships with their children, with their families and with society, in general.

\section{References}

[1] American Psychiatric Association, (2013). Diagnostic and Statistical Manual of Mental Disorders, $5^{\text {th }}$ edition.

[2] Azeem, M.W., Dogar, I.A., Shah, S., Cheema, M.A., Asmat, A., Akbar, M., Kousar, S., Haider, I.I. (2013). Anxiety and Depression among Parents of Children with Intellectual Disability in Pakistan. Journal of the Canadian Academy of Child and Adolescent Psychiatry, 22(4), pp. 290-295

[3] Bitsika, V., Sharpley, C.F. (2004). Stress, Anxiety and Depression Among Parents of Children with Autism Spectrum Disorder. Journal of Psychologists and Counselors in Schools, 14(2), pp. 151-161

[4] Bystritsy, A., Khalsa, S.S., Cameron, M.E., Schiffman, J. (2013). Current Diagnosis and Treatment of Anxiety Disorders. Pharmacy and Therapeutics, 38(1), pp.30-38, 41-44, 57

[5] Cuijpers, P. (2011). The patient perspective in research on major depression. BMC Psychiatry, 11, pp.89

[6] Davis, M., Walker, D.L., Miles, L., Grillon, C. (2010). Phasic vs sustained fear in rats and humans: role of the extended amygdala in fear vs anxiety. Neuropsychopharmacology, 35(1), pp. 105-135

[7] Enăchescu, C. (2007). Tratat de psihopatologie. Iași: Ed. Polirom

[8] Feizi, A., Najmi, B., Salesi, A., Maryam, C., Hoveidafar, R. (2014). Parenting stress among mothers of children with different physical, mental and psychological problems. Journal of Research in Medical Sciences, 19(2), pp. 145-152 
[9] Gallagher, S., Phillips, A.C., Oliver, C., Carroll, D. (2008). Predictors of psychological morbidity in parents of children with intellectual disabilities. Journal of Pediatric Psychology, 33, pp. 1129-1136

[10] Gavin, A., Creamer, M., Crino, R. (2007). Psihoterapia tulburărilor anxioase. Iași: Ed. Polirom

[11] Grecu, G.I., Gaboș, G.M., Raduly, L. (2007). Depresia - Metode de diagnostic și tratament. Tg. Mureș: Ed. Farmamedia

[12] Gilbert, P. (2011). Depresia: psihoterapie și consiliere. Iași. Ed. Polirom

[13] Grillon, C., Ameli, R., Woods, S.W., Merikangas, K., Davis, M. Fear-potentiated startle in humans: effects of anticipatory anxiety on the acoustic blink reflex. Psychophysiology, 28(5), pp. 588-595

[14] Grillon, C. (2008). Models and mechanisms of anxiety: evidence from startle studies. Psychopharmacology, 199(3), pp. 421-437

[15] Holdevici, I. (2002). Psihoterapia anxietății. București: Ed. DuAL Tech

[16] Holdevici, I. (2000). Gândire pozitivă. Ghid practic de psihoterapie raționalemotivă și cognitiv-comportamentală. București: Ed. DuAL Tech

[17] Ionescu, Ș., Blanchet, A., Montreuil, M., Doron, J. (2013). Tratat de psihologie clinică și psihopatologie. București: Ed. Trei

[18] Kanter, J.W., Busch, A.M., Weeks, C.E., Landes, S.J. (2008). The Nature of Clinical Depression: Symptoms, Syndromes, and Behavior Analysis. The Behavior Analyst, 31(1), pp. 1-21

[19] Kazmi, S.F., Perveen, S., Karamat, S., Mehboob Khan, A. (2014). Depression and Quality of Life of Parents of Disabled Children. Annals of Pakistan Institute of Medical Sciences, 10, pp. 125-127

[20] Klein, D.F. (2002). Historical aspects of anxiety. Dialogues in clinical neuroscience, 4(3), pp. 295-304

[21] Masulani-Mwale, C., Kauye, F., Gladstone, M., Mathanga, D. (2018). Prevalence of psychological distress among parents of children with intellectual disabilities in Malawi. BMC Psychiatry, 18, p. 146

[22] Rezendes, D.L., Scarpa, A. (2011). Associations between Parental Anxiety/Depression and Child Behavior Problems Related to Autism Spectrum Disorders: The Roles of Parenting Stress and Parenting Self-Efficacy. Autism Research and Treatment, retrieved from https://www.hindawi.com/journals/aurt/2011/395190/, accessed on 7.02.2019

[23] Riedesser, P., Fisher, G. (2007). Tratat de Psihotraumatologie. București: Ed. Trei

[24] Robinson, O.J., Vytal, K., Cornwell, B.R., Grillon, C. (2013). The impact of anxiety upon cognition: perspectives from human threat of shock studies. Frontiers in Human Neuroscience, 7, pp. 203

[25] Rus, M., Tasențe, T., Rus, C. V., Preventive behaviors and attitudes of the children as active participants in road traffic, Acta Universitatis Danubius. Administratio 11(1) 2019

[26] Seltzer, M.M., Greenberg, J.S., Floyd, F.J., Pettee, Y., Hong, J. (2001). Life course impacts of parenting a child with a disability. American Journal of Mental Retardation, 106(3), pp. 265-286

[27] Sîntion, F., Călin, M.F. (2014). Methodology of research in socio-human sciences. Constanța: Ovidius University Press 
[28] Tabassum, R., Mihsin, N. (2013). Depression and anxiety among parents of children with disabilities: a case study from developing world. International Journal of Environment, Ecology, Family and Urban Studies, 3(5), pp. 33-40

[29] Uskun, E., Gundogar, D. (2010). The levels of stress, depression and anxiety of parents of disabled children in Turkey. Journal of Disability and Rehabilitation, 32(23), pp. 1917-1927

[30] Walker, D., Leach, J. (2014). Anxiety: Etiology, Treatment, and Christian Perspectives. Journal of Christian Nursing, 31(2), pp. 84-91

[31] https://www.childresearch.net/papers/rights/2013 01.html, accessed on 7.02.2019 